\title{
A PRÁTICA GERENCIAL DO ENFERMEIRO NO PROCESSO DE CUIDAR
}

[Nursing management practice in the caring process]

Mariluci Hautsch Willig*

Maria Helena Lenardt*

RESUMO: Trata-se de um artigo que tem como objetivo desenvolver uma reflexão crítica a respeito da prática profissional do enfermeiro no gerenciamento do processo de cuidar e dos instrumentos utilizados no desempenho deste papel. As reflexões desenvolvidas foram embasadas na literatura atual, segundo o pensamento de diferentes autores. A partir dos achados na literatura, percebe-se a importância de se adequar os "instrumentos próprios do gerenciamento do processo de cuidar", com a finalidade de prestar assistência planejada e de qualidade ao paciente. A adoção de uma prática gerencial participativa pelo enfermeiro mostra-se como estratégia de articulação na busca do envolvimento e participação da equipe de enfermagem no processo assistencial.

PALAVRAS-CHAVE: Gerenciamento clínico, Cuidados de enfermagem; Enfermagem prática; Prática profissional.

\section{INTRODUÇÃO}

Discorrer sobre a prática gerencial do Enfermeiro implica conhecer e refletir sobre sua história e os princípios da Enfermagem, sobretudo as características que a identificam como profissão. Dentre as condições estabelecidas para esse reconhecimento estão as de possuir "código e legislação específica", que amparam o exercício profissional, o de agrupar-se em "entidades de classe" como ABEN/ COFEN e a possibilidade de capacitação das categorias existentes através da "educação formal" (TRENTINI; PAIM, 1992, p. 28-33).

O início da trajetória administrativa da enfermagem brasileira, reporta-se a 1955, quando foi sancionada a Lei 2.604 pelo então Presidente da República João Café Filho, que regulava o exercício da Enfermagem profissional no Brasil; nesta o artigo $3^{\circ}$ propõe como atribuição do Enfermeiro a direção dos serviços hospitalares e de saúde pública.

* Mestranda em Enfermagem pela UFPR. Membro do GEMSA.

** Docente da UFPR. Doutora em Enfermagem pela UFSC. Membro do GEMSA.
A resolução n. ${ }^{\circ}$ 04/1972 do Conselho Federal de Educação, sobre o currículo mínimo dos cursos de Enfermagem e Obstetrícia, já apontava a Administração Aplicada à Enfermagem como disciplina integrante do tronco principal (LIRA; BOMFIM, 1989).

Ao longo do tempo, disciplinas de administração e planejamento passam a integrar o currículo de graduação em Enfermagem, com o objetivo de preparar e direcionar os Enfermeiros para desempenhar o papel de administrador do processo de trabalho.

As enfermeiras eram preparadas para ocupar cargos de chefia sendo as atividades assistenciais executadas predominantemente pelos atendentes e auxiliares de enfermagem (TRENTINI; PAIM, 1992).

A estrutura organizacional das instituições prestadoras de assistência contempla o modelo de administração clássica, onde a hierarquia predomina na divisão do trabalho, e a função do enfermeiro é voltada à administração do serviço, ao controle de recursos humanos, físicos e materiais. O enfermeiro é visto como centralizador do poder decisório e fiscalizador do processo assistencial. O modelo administrativo vigente, essencialmente burocrático, já não encontra eco junto à Enfermagem, que anseia por um gerenciamento mais flexível, que permita ir além de receber e executar ordens.

Segundo ERDMANN \& PINHEIRO (1998, p. 89), "o grande desafio no gerenciamento do cuidado está em oportunizar ambiente e ações que propiciem um cuidado criativo, humano e de co-participação com as pessoas da relação neste processo em que o aceitar, o decidir e o liderar centralizam as estratégias do gerenciamento".

No entender de LUNARDI FILHO; LUNARDI (1996, p. 30), "o reconhecimento da administração da assistência como papel fundamental da existência profissional, tendo como objeto de trabalho o homem e o ambiente, justifica-se porque se constitui não num fim determinado pela administração superior, mas porque se constitui em meio e instrumento para alcançar a adequada assistência desejada para o cliente". 
A temática deste estudo e controvérsias advindas dele reportam à época do curso de graduação, quando o enfoque dado às disciplinas de Planejamento e Administração em Saúde priorizava a administração geral, dissociada do gerenciamento do cuidado.

Minha caminhada profissional, iniciada em 1997, acompanha este mesmo modelo, pois a instituição em que atuo, em sua estrutura organizacional, adota o modelo de administração clássica na divisão do trabalho, onde desempenho a função de enfermeira administrativa, responsável pelo gerenciamento de recursos humanos, ambientais e materiais de uma unidade.

Tal condição foi também constatada quando da atuação como professora substituta do Curso de Graduação em Enfermagem, nas disciplinas de Planejamento e Administração em Saúde e Administração da Assistência em Saúde, acompanhando e supervisionando os alunos, nas aulas práticas desenvolvidas no contexto de um hospital de ensino, pude perceber que as funções dos enfermeiros não se diferenciavam das por mim exercidas neste mesmo contexto. Ao retornar, posteriormente à prática docente como mestranda, constatei que o foco das disciplinas de Planejamento e Administração esboçavam um novo olhar, numa tentativa de aproximação do cuidar/administrar.

O distanciamento entre o administrar e o cuidar vivenciado no cotidiano de trabalho, vem gerando inquietações pessoais e profissionais, e impondo um repensar da prática administrativa voltada à assistência, procurando resgatar o papel do enfermeiro como gerente do cuidado.

O gerenciamento participativo, que advoga a descentralização do poder decisório, é uma estratégia a ser utilizada pelo enfermeiro na busca de uma transformação do processo gerencial. Como exemplos, a realização conjunta das escalas de trabalho, a construção de planejamento que envolve ações sugeridas pela equipe e a delegação de tarefas são atividades que sendo compartilhadas com a equipe de enfermagem, denotam a valorização dos profissionais da equipe, que certamente mostrarão mais satisfação e qualidade na prestação do cuidado.

Este artigo tem como objetivo desenvolver uma reflexão crítica a respeito da prática profissional do enfermeiro no gerenciamento do processo de cuidar e dos instrumentos utilizados no desempenho deste papel.

\section{A PRÁTICA DO ENFERMEIRO GERENCIAL}

O gerenciamento no processo de trabalho da Enfermagem tem como foco principal a organização da assistência, isto é, o planejamento de ações compartilhadas de modo que a equipe de enfermagem, sob a liderança do enfermeiro, desenvolva o processo de trabalho com eficiência e qualidade com a finalidade de satisfazer as necessidades do paciente assistido.

Ao descreverem o processo de trabalho em Enfermagem na área hospitalar, CASTELLANOS et al. (1989, p.150), apontam duas características: "o processo de trabalho 'cuidar' e o processo de trabalho 'administrar'. Os principais instrumentos do processo de trabalho cuidar são: a observação, o levantamento de dados, o planejamento, a evolução, a avaliação, os sistemas de assistência, os procedimentos técnicos e de comunicação e interação entre pacientes e trabalhadores da Enfermagem e entre os diversos profissionais. Citam como objetos de trabalho do enfermeiro no processo de 'administrar", o de organizar a assistência e proporcionar a qualificação do pessoal de enfermagem através da Educação Continuada", apropriandose para isto dos próprios modelos e métodos de administração, da força de trabalho da Enfermagem e dos equipamentos e materiais permanentes.

Segundo CHIAVENATO (2000, p. 330), a função administrativa no nível intermediário das instituições (departamentos, serviços) recebe a denominação de gerência e se incumbe de conduzir as pessoas para o alcance dos objetivos institucionais , é "uma atividade voltada para as pessoas e se fundamenta na motivação, na liderança e na comunicação".

Gerenciar é estar com as pessoas. O processo relacional acontece na interação chefia-equipe, no qual o gerente atua como mediador, compartilha e estimula a participação do pessoal de Enfermagem nos processos decisórios, propõe desafios e não respostas prontas, e divide o poder e o status. Estes comportamentos geram o comprometimento da equipe e conseqüentemente a melhoria do cuidado ao paciente.

O cuidado se insere nesta área de forma relevante, pois da atuação do enfermeiro e do papel que desempenha depende o sucesso do planejamento e o gerenciamento do processo em si, isto é, do processo de trabalho em Enfermagem. O coordenador do processo de cuidar, cuida da equipe de enfermagem sob sua responsabilidade, interagindo, identificando e intervindo adequadamente em situações cotidianas. Precisa dominar a dinâmica do cuidado e do serviço, bem como o contexto da prática. Uma prática em movimento, passível de mudanças, que gerem transformações, garantindo assim um cuidado profissional.

Para IDE (2001, p. 160), o enfermeiro tem por competência a coordenação do processo de cuidar e como instrumentos: "a sistematização do cuidar, a mediação das relações profissionais e a representação da sua equipe junto às esferas de gestão, interface com o processo de trabalho 
administrar". Discorrendo sobre o processo de cuidar, IDE (2001, p. 160) afirma ainda que este tem como características a "seqüência dinâmica e sistematizada de ações necessárias e suficientes para a construção, desempenho e validação do trabalho da equipe de enfermagem".

O trabalho gerencial se dá de forma imediata, representada pela organização e coordenação do processo de cuidar e na disponibilização dos meios para que o processo aconteça. Como forma mediata está o desenvolvimento de condições para a efetivação do processo de cuidar (CASTELLANOS et al., 1989).

\section{LIMITAÇÕES E CONTROVÉRSIAS DA PRÁTICA GERENCIAL}

Funções burocráticas, adoção de modelos organizacionais com predominância do modelo médico, são algumas das questões que dificultam o desempenho de um trabalho gerencial voltado ao cuidado.

No entendimento de ALVARES et al (2003, p. 65), "o enfermeiro vêm assumindo mais atividades administrativas em relação ao cuidado do que aquelas de cuidado direto ao paciente". A formação profissional Ihe impõe como foco principal o cuidado, por outro lado o contexto de trabalho o direciona para as questões do administrar este cuidado. Existe um descompasso entre o processo de formação e a prática do enfermeiro, o que resulta em tensões, desmotivação e conflitos.

Segundo Caldonha, apud ANTUNES et al (2001), a Enfermagem, desde a sua origem como profissão, enfrenta dificuldades para delimitar o papel do Enfermeiro, pois este vem assumindo diferentes atividades voltadas à assistência, outras eminentemente administrativo-burocráticas, que são direcionadas às necessidades da instituição, e outras que poderiam ser delegadas.

Porquanto, ainda, o trabalho diário da enfermagem comporta a administração de recursos para que as condições à realização do trabalho de todos os profissionais de saúde sejam garantidas. $\mathrm{O}$ trabalho administrativo do enfermeiro vem assumindo novas características devido às estruturas cada vez mais complexas das instituições de Saúde de grande porte, assim como, a administração dos cuidados foi acrescida de funções de gerência com vistas a concatenar o próprio trabalho de enfermagem com os trabalhos dos diversos profissionais especializadas como, psicólogo, fisioterapeuta, assistente social, nutricionista e médico.

Entretanto, esses profissionais vêm limitando suas presenças e as suas tarefas mais rotineiras. Como conseqüência, a enfermeira é que sustenta esse tipo de trabalho.
Por outro lado, LACERDA \& COSTENARO (1999) dizem que a falta de tempo, é uma desculpa na vida do Enfermeiro, por não passar mais tempo próximo ao cliente. Os empregadores das instituições de saúde, ao longo do tempo, imputaram ao Enfermeiro um papel que denota subserviência aos modelos médicos e institucionais, sendo estes utilizados como fiscalizadores e mantenedores da ordem e das normas estabelecidas pelo empregador.

O enfermeiro ao mesclar no seu cotidiano atividades de gerenciamento do serviço e do gerenciamento do cuidado, caba por se distanciar do paciente, pois não consegue acompanhar e avaliar a execução do cuidado planejado.

No entender de CASTELLANOS et all. (1989), o processo administrativo é o mais presente no dia-a-dia do Enfermeiro que, na sua maioria, o negam, com a justificativa de que devem atuar no cuidado direto. O enfermeiro deve assumir este papel de administrar e vê-lo como desafio, pois dele depende um cuidar com qualidade e resolutividade, mesmo tratando-se de cuidado indireto, sendo a supervisão do processo de trabalho outro desafio.

O grau de autoridade e o poder de decisão, utilizados pelo enfermeiro na organização do trabalho de enfermagem, destacam a presença de autonomia deste profissional em relação à Instituição ou a quem ele está subordinado diretamente. A autonomia na tomada de decisões do enfermeiro gerencial na organização do trabalho de enfermagem e do próprio estilo de gerenciar, depende, muitas vezes, das normas estabelecidas pela Instituição, o que se torna um entrave para que as transformações necessárias aconteçam.

Ao ser questionada sobre as principais dificuldades enfrentadas pelo Enfermeiro na implantação de uma proposta de gerenciamento participativo, GAIDZINSKI (2002, p. 1), afirma:

Ainda há muita resistência às inovações e poucos são os que tomam a iniciativa de adotar uma abordagem gerencial inovadora para direcionar a sua prática. A ausência de trabalho em equipe; quadro de pessoal insuficiente; excesso de burocratização; falta de autonomia para o enfermeiro; a presença de estrutura hierarquizada, rígida e pouco interativa e a falta de informações para a tomada de decisões, são fatores que caracterizam o modelo gerencial tradicional, e que, estando ainda fortemente arraigados na prática, têm dificultado o desenvolvimento de propostas participativas.

O caminho para o Enfermeiro resgatar seu papel e seu espaço se fará por meio do conhecimento científico, adequando os instrumentos de gerência e de poder a serviço da Enfermagem, de seus fundamentos e finalidades (LACERDA; COSTENARO, 1999). 


\section{INSTRUMENTOS E ESTRATÉGIAS DO PROCESSO GERENCIAL}

No desenvolvimento histórico da Enfermagem, esta tem procurado acompanhar as transformações tecnológicas e sociais. Diante dos serviços existentes no âmbito da Saúde, o enfermeiro-gerente se configura como peça essencial no processo de trabalho da enfermagem, na promoção do cuidado efetivo e de qualidade. Para o desenvolvimento das habilidades de liderança no enfermeiro, é necessário "elevar a consciência dos enfermeiros por meio de uma contínua crítica ao sistema atual, e a de oferecer fundamentos lógicofilosóficos e práticos para mudanças essenciais, baseadas em valores da enfermagem e no papel central que a enfermagem assume no processo de assistência à saúde" (Edwards apud MARQUIS; HOUSTON, 1999, p.27).

Os diferentes olhares quanto às concepções de homem e sociedade e o entendimento do que é saúde, implicam a mudança da função social do enfermeiro. Ao se referir às características deste novo profissional, BORDENAVE (1996, p.1) cita o conceito elaborado pela REDE DE ENFERMAGEM DAAMÉRICA LATINA, que assim explicita: "Queremos um novo profissional, capaz de dirigir sua prática para um trabalho integral que permita inovar na atenção, que desenvolva seu pensamento crítico reflexivo e que tenha uma participação efetiva na tomada de decisões, em conjunto com os diferentes atores implicados na atenção à saúde humana".

O trabalho gerencial se configura como um desafio às capacidades e habilidades do Enfermeiro, que brotam e se desenvolvem no dia-a-dia. No gerenciamento do processo de cuidar, o enfermeiro se utiliza de instrumentos e estratégias que o auxiliarão para atingir os objetivos e as metas propostas. A ação gerencial, centrada nos princípios de participação e envolvimento da equipe de enfermagem, é uma estratégia a ser utilizada pelo enfermeiro que pretende realizar uma gestão inovadora.

Ao discorrer sobre a gerência participativa, CIAMPONE (2002, p. 8), afirma:

A gerência participativa está fundamentada no humanismo, pois é pautada no respeito e integração dos valores humanos, nas necessidades das pessoas e do trabalho. Considera o trabalhador como ser atuante na organização, com capacidade de desenvolver o seu papel com autonomia e de participar efetivamente nas tomadas de decisões relacionadas aos processos de trabalho dos serviços. A estrutura organizacional é flexível e adaptável, há maior confiabilidade nas interações informais e as decisões são descentralizadas. Esta proposta propicia o crescimento pessoal e profissional, contribuindo para que o trabalhador se sinta mais motivado e reconhecido.
No entendimento de BORDENAVE (1996, p. 1), a enfermeira deve assumir sua função de agente mediador do processo de trabalho em enfermagem numa visão de enfermagem como "prática social"; e para isto precisa apropriar-se das ferramentas típicas da "mediação social: a comunicação, a participação e o planejamento".

Ao discorrerem sobre a importância do planejamento, FUGITA \& FARAH (2000, p.108) afirmam que este é: "um instrumento essencial para a prática da enfermagem [...], o enfermeiro deve conhecer este instrumento, utilizando-o com propriedade para atingir seus objetivos profissionais, obtendo, assim, um resultado final produtivo em sua atuação".

O planejamento se desenha como a função primordial do gerenciamento, pois ele subsidia todas as demais; ele predetermina o caminho das ações para alcançar os objetivos esperados.

De acordo com CHIAVENATTO (2000, p. 169), o planejamento é "a função administrativa que determina antecipadamente o que se deve fazer e quais os objetivos que devem ser alcançados". É um modelo teórico para uma ação futura.

A participação como instrumento gerencial se configura na distribuição do poder entre os componentes da equipe de enfermagem. Tal exigência é conseqüência das novas tendências da divisão do poder entre pessoas e grupos.

Para BORDENAVE (1996, p.6), a participação é "uma necessidade fundamental de todos os seres humanos".

Administrar implica comunicação, sendo que esta se processa na troca de idéias e informações. Vai muito além de meras palavras. Faz-se presente em todos os aspectos das ações e relações do dia-a-dia. A vida e o trabalho giram em tomo dela. É ancoragem no desenvolvimento da compreensão e o respeito mútuos, tão indispensável as nossas relações com colegas de trabalho e com os pacientes (KRON; GRAY, 1994).

Para BITTES JUNIOR \& MATHEUS (2000), o conhecimento da comunicação é o processo que viabiliza a qualidade das relações interpessoais, ou seja, com a equipe de saúde, na descrição dos cuidados prestados ao paciente, família e comunidade.

Ao discorrer sobre a importância da comunicação, ANTUNES (1997, p. 17) sugere:

O enfermeiro deve implementar uma comunicação aberta, franca natural e eficaz de forma a eliminar os ruídos ou bloqueios, para facilitar o fluxo em todas as direções: descendente, ascendente e lateral. Ela permite iniciar e conduzir os esforços, implantar novas metodologias e novas técnicas de trabalho, se preocupa 
em divulgar as informações. o conhecimento disponível e planos de trabalho em todos os níveis. Desta forma a comunicação é um fator determinante de sucesso ou insucesso na ação gerencial do enfermeiro.

A comunicação na Enfermagem, na visão de BITTES JUNIOR \& MATHEUS (2000), se mostra como necessidade humana básica, instrumento este que a enfermeira deve utilizar com competência. A comunicação vista como ferramenta contribui para a realização e aperfeiçoamento do saber-fazer profissional.

Na função administrativa do enfermeiro, além das ferramentas citadas, acrescentam-se outras mais como a liderança, a motivação, a supervisão e a avaliação.

A liderança é instrumento necessário no desenvolvimento do trabalho em equipe, para a tomada de decisões; é preciso conhecer as normas da instituição, possuir conhecimento técnico-científico pertinente à área de enfermagem e também dominar teorias administrativas inovadoras.

Ao discorrer sobre a importância da liderança para o desenvolvimento de um gerenciamento efetivo, ANTUNES (1999, p.26) afirma: "a liderança é um fator fundamental ao bom gerenciamento do serviço de enfermagem e conseqüente a qualidade da assistência prestada ao paciente. Por isto é indispensável que o enfermeiro, que a todo momento atua como líder no desempenho de suas atividades, esteja capacitado para atuar como 'líder competente' nas diferentes situações profissionais."

Por meio da liderança que exerce junto à equipe de enfermagem, o enfermeiro deve estar atento às questões que podem contribuir para o desencadeamento de situações que venham a desmotivar o grupo, porque segundo BERGAMINI (1986), a motivação é algo interno, pessoal; logo, não pode ser desenvolvida, e sim despertada e conservada pelo enfermeiro, com o conhecimento e atenção às necessidades individuais da equipe.

O enfermeiro, na visão de CUNHA (1991, p. 128), "ao desenvolver a função de supervisão deve tentar, a partir do conhecimento das características individuais de seus funcionários e dos objetivos do serviço de enfermagem, adequar o tipo de relacionamento, e o tipo de atividades a serem desenvolvidas, propiciando com isso melhor adaptação do homem ao trabalho". A supervisão, com enfoque na orientação e como facilitadora do processo de trabalho, coopera para que as pessoas se mantenham motivadas e ocorra crescimento profissional.

Para ZANEI et al. (2000, p. 120), "no gerenciamento global da assistência de enfermagem, a utilização da avaliação pelo enfermeiro, como instrumento de trabalho, envolvendo estrutura, processo e resultado, permitirá a realização daquilo que é esperado por toda a equipe de enfermagem, ou seja, atendimento humanizado individualizado e com qualidade garantida". A avaliação deve estar presente em todas as fases do processo gerencial, de forma contínua, permitindo assim os ajustes necessários a cada ação desenvolvida.

Dentre os instrumentos indispensáveis para que o gerenciamento aconteça satisfatoriamente, é necessário também que o enfermeiro se utilize do trabalho em equipe, pois deste depende a qualidade dos serviços. Segundo BERSUSA \& RICCIO (2000, p. 76), "o homem não consegue trabalhar só, o trabalho em equipe é um requisito vital para a obtenção de resultados, quando se considera o potencial sinergético dos grupos: um conjunto de pessoas tem propriedades e qualidades coletivas que elas separadamente não manifestam. O trabalho em equipe é um instrumento básico para que o enfermeiro resgate a sua especificidade enquanto profissão".

A equipe de enfermagem tem como objeto principal o cuidar. O espírito de equipe e de união devem permear o processo de assistência, para que as diferenças técnica, social e psicológica não comprometam o fazer coletivo. Como grupo as pessoas interagem, e se relacionam: sentimentos de escuta, de entendimento e aceitação permeiam o fazer cotidiano. No entender de BERSUSA \& RICCIO (2000, p.77), "a interação pode ser a essência da vida social. Os indivíduos agregados tornam-se grupo e sociedade, a partir do relacionamento de seus membros, sendo a reciprocidade de relações o entrelaçamento de atos, idéias e sentimentos". O enfermeiro, ao gerenciar, precisa valorizar e promover o desenvolvimento da interação e cooperação grupal, respeitando as diferenças individuais, favorecendo a formação de vínculos afetivos.

A criatividade, como ferramenta, se expressa na resolução de conflitos e nas inovações de rotinas, tão importantes para a enfermagem. Assim como, para SÁ \& FUGITA (2000), a criatividade não deve ser utilizada apenas na resolução de problemas, mas também o enfermeiro deve utilizar seu talento criativo na associação de pensamentos e reflexões sobre a prática cotidiana, criando formas alternativas para o seu crescimento pessoal e profissional.

O êxito gerencial dependerá do conhecimento dessas estratégias, instrumentos e ferramentas pelo enfermeiro e da forma como este se utiliza desses recursos no seu processo de trabalho. 


\section{CONSIDERAÇÕES FINAIS}

Essas reflexões, por meio do levantamento de conceitos, idéias e proposições de diferentes autores, envolvendo a temática do gerenciamento do processo de cuidar em enfermagem, permitiram o repensar sobre questões determinantes do processo gerencial.

Na sua prática cotidiana é essencial que o enfermeiro se aproprie dos instrumentos gerenciais, na tentativa de inovar e transformar o processo de cuidar. Para tanto é necessário que este desenvolva suas habilidades gerencias, ancorandose nos conhecimentos técnico-científico-filosóficos, e na participação e envolvimento da equipe de enfermagem na construção e desenvolvimento das ações do processo de cuidar. O grau de envolvimento e de comprometimento da equipe de enfermagem influencia sobremaneira o alcance dos objetivos e resultados a serem alcançados.

Penso que o papel imposto pela instituição, direcionando o enfermeiro para a realização de funções essencialmente administrativo-burocráticas, é fator limitante no desenvolvimento do trabalho gerencial centrado no cuidado. Para diminuir este impasse, e não usar a falta de tempo como justificativa, a estratégia é a realização de uma gestão participativa, com a colaboração da equipe na tomada de decisões e a delegação de funções que podem ser desenvolvidas pelo pessoal de nível técnico com ou sem supervisão. O fazer compartilhado, envolvendo o enfermeirogerente e a equipe de enfermagem, resulta em aproximação e interação que facilita e minimiza os conflitos existentes, gerados num modelo de gerência participativa.

Creio que o enfermeiro deve buscar a transfiguração do processo de cuidar, evitando ações rotineiras que não permitem que aflore o desenvolvimento individual e coletivo. É importante a utilização pelo enfermeiro dos instrumentos da administração, como o planejamento, a coordenação e a avaliação no processo de cuidar, instrumentos resultantes dos conhecimentos e habilidades que permitem o exercício da prática profissional. O aperfeiçoamento permanente, a investigação científica na busca de conhecimentos, a utilização de comunicação efetiva, o respeito pela individualidade, a possibilidade do crescimento coletivo por meio de reflexão e postura crítica, o desenvolvimento da criatividade a partir de liberdade e responsabilidade, atitudes de escuta, compreensão e aceitação e o desenvolvimento de vínculos afetivos, são comportamentos esperados e que devem ser instrumentalizados num modelo de gestão participativa.

Acredito que o êxito no gerenciamento depende da adoção de nova postura por parte do enfermeiro, compartilhando o poder decisório, abandonando ou diminuindo as atividades burocráticas, assumindo seu papel administrativo no processo de cuidar, com autonomia, liderança e criatividade, porquanto resultará mais harmonia entre a equipe de enfermagem e a melhoria na qualidade da assistência prestada ao paciente.

ABSTRACT: It's an article which objectifies to develop a thought-provoking analysis about nursing professional practice in managing the caring process as well as the tools used to perform this role. The developed reflections were grounded by current literature according to different authors' thought. Findings in literature point out the importance of adequating "proper management tools in the caring process" aiming to deliver planned, first-quality care to the patient. Nurses' adoption of a participative management practice brings about an articulating strategy in the search for involvement and participation of the nursing team in the caring process.

KEY WORDS: Discase management; Nursing practical; Professional.

\section{REFERÊNCIAS}

1 ALVARES, L. H. et al. Grupo de estudos articulando processos de educação, cuidado e gerenciamento em enfermagem. In: TRENTINI, M.; PAIM, L. (Org.). Pesquisa e assistência: experiências com grupos de estudo na enfermagem. Curitiba: Champagnat, 2003. p. 16-21.

2 ANTUNES, V. A. et al. A ação gerencial do enfermeiro situação ideal $x$ realidade. Rev. Téc. Enf. Nursing, São Paulo, v. 4 n. 35, abr., 2001. p. $16-21$

3 BERGAMINI, C. W. Motivação. São Paulo: Atlas, 1986

4 BERSUSA, A. A. S. ; RICCIO, G. M. G. Trabalho em equipe: instrumento básico de enfermagem. In: CIANCIARULLO, T. I. (Org.). Instrumentos básicos para o cuidar: um desafio para a qualidade de assistência. São Paulo: Atheneu, 2000. p. 65.

5 BITTES JUNIOR, A.; MATHEUS, M. C. C. Comunicação como instrumento básico em enfermagem. In: CIANCIARULLO, T. I. (Org.). Instrumentos básicos para o cuidar: um desafio para a qualidade de assistência. São Paulo: Atheneu, 2000. p. 61-73.

6 BORDENAVE, J. D. A enfermeira como agente mediador e suas ferramentas operativas: comunicação, participação e planejamento. Rio de Janeiro, 1996

7 CASTELLANOS, B. E. P. et al. Os desafios da enfermagem para os anos 90. In: CONGRESSO BRASILEIRO DE ENFERMAGEM, 41, 1989. Florianópolis. Anais. Florianópolis: Aben, 1989. p. 148-169.

8 CHIAVENATO, I. Administração, teoria, processo e prática. São Paulo: Makron Books, 2000.

9 CIAMPONE, M. H. T. Administração em enfermagem. Rev. Enf. Atual, Rio de Janeiro, a. 2, v. 2, n.10, jul./ago., 2002. p. 06-13.

10 CONSELHO FEDERAL DE ENFERMAGEM, Lei do Exercício Profissional. Lei n. ${ }^{0} 7.498,25$ de junho de 1986, Dispõe sobre a regulamentação do exercício da enfermagem e dá outras providências. Brasília, 1987. 
11 CUNHA,C. C. Supervisão em enfermagem. In: KURCGANT, P. (Org.) Administração em enfermagem. São Paulo: EPU, 1991. p. 117-132.

12 ERDMANN, L. A.; PINHEIRO, I. G. Gerenciamento do cuidado em enfermagem: questionando estratégias. Cogitare. Enferm., Curitiba, v. 3, n.1, p. 89 -96, jan./jun., 1998.

13 FUGITA, R. M. I.; FARAH, O. G. O planejamento como instrumento básico do cuidado. In: CIANCIARULLO, T. I. (Org.). Instrumentos básicos para o cuidar: um desafio para a qualidade de assistência. São Paulo: Atheneu, 2000. p. 99-109.

14 GAIDZINSKI, R. R. Administração em enfermagem. Rev. Enf. Atual, Rio de Janeiro, v. 2, n.10, p. 6-13, jul./ago., 2002.

15 IDE, C. A. C. A Coordenação do processo de cuidar. In: IDE, C.A.C.; DOMENICO, E. B. L. Ensinando e aprendendo um novo estilo de cuidar. São Paulo: Atheneu, 2001. p. 153- 163.

16 KRON, T.; GRAY, A Administração dos cuidados de enfermagem ao paciente: colocando em ação as habilidades de liderança. Rio de Janeiro: Interlivros, 1999.

17 LACERDA, M. R. COSTENARO, R. G. S. O cuidado como manifestação do ser e fazer da enfermagem. Vydia. Santa Maria, v. 18, n. 32, jul./ dez.,1999. p 7-13.

18 LIRA, N. F de.; BONFIM, M. E. História da enfermagem e legislação. Rio de Janeiro: Cultura Médica, 1989.
19 LUNARDI FILHO, D. W.; LUNARDI, V. L. Uma nova abordagem no ensino da enfermagem e de administração em enfermagem como estratégia de (re)orientação da prática profissional do enfermeiro. Texto Contexto Enf. Florianópolis, v. 5, n. 2, jul./dez., 1996. p. 20-34.

20 MARQUIS, B. L.; HUSTON, C. J. Administração e liderança em enfermagem: teoria e aplicação. Porto Alegre: Artmed, 1999.

21 SÁ, A. C. A.; FUGITA, R. M. I.. A criatividade como instrumento básico de enfermagem. In: CIANCIARULLO, T. I. (Org.). Instrumentos básicos para o cuidar: um desafio para a qualidade de assistência. São Paulo: Atheneu, 2000. p. 47-60.

22 TRENTINI, M.; PAIM, L. Enfermagem ciência ou profissão? Rev. Gaúcha Enf., Porto Alegre, v. 13, n. 1, p. 28-33. jan.,1992.

23 ZANEI, S. S. V. et al. Avaliação: um instrumento básico de enfermagem. In: CIANCIARULLO, T. I. (Org.). Instrumentos básicos para o cuidar: um desafio para a qualidade de assistência. São Paulo: Atheneu, 2000. p. 111-135.

Endereço da autora: Rua Alberto Manoel Glaser, 10 - sobrado 2 82600-080 - Vila Tingui - Curitiba - PR E-mail: marilucihw@zipmail.com.br 